Fecha de recepción: junio 2020

Fecha de aceptación: agosto 2020

Versión final: septiembre 2020

\section{A Infografia como ferramenta de comunicação e inclusão}

Marcus Aurelius Lopes Domiciano ${ }^{(1)}$ e Vânia Cristina Pires Nogueira Valente ${ }^{(2)}$

Resumo: Examina-se como o infográfico se beneficia do avanço tecnológico no processo de comunicação e inclusão das minorias. O objetivo é analisar algumas peças infográficas produzidas no Brasil, Argentina e México para detectar as suas funcionalidades como ferramenta tecnológica que se apoia na complementaridade entre verbal e visual para transmitir informações. A evolução dos infográficos no Brasil tem colocado o país na vanguarda da produção na América Latina, extrapolando o uso inicial em jornais e revistas para abarcar economia, marketing, esportes, saúde, ensino, aprendizagem e incentivar as relações pessoais. Discutem-se as regras éticas para apresentação de infográficos e de que maneira as ferramentas online têm colaborado para que leigos no assunto possam se envolver na produção. Ao incorporar vídeos, aúdios, interatividade, hipertextos, realidade aumentada e outras tecnologias, o infográfico assume sua multimidialidade e abre caminho para possíveis novas mudanças no processo de comunicação.

Palavras chave: infográfico - inclusão - ferramenta de comunicação.

[Resumos em espanhol e inglês na página 63]

${ }^{(1)}$ Doutorando no Programa de Pós-Graduação em Mídia e Tecnologia (PPGMiT), da Faculdade de Arquitetura, Artes e Comunicação (FAAC), na Universidade Estadual Paulista Júlio de Mesquita Filho (Unesp), campus de Bauru, estado de São Paulo, Brasil | marcus. domiciano@unesp.br

(2) Profa Dra do Programa de Pós-Graduação em Mídia e Tecnologia (PPGMiT), da Faculdade de Arquitetura, Artes e Comunicação (FAAC), na Universidade Estadual Paulista Júlio de Mesquita Filho (Unesp), campus de Bauru, estado de São Paulo, Brasil | vania. valente@unesp.br 


\section{Introdução}

O desenvolvimento científico, os novos saberes acumulados com o passar dos anos, os novos produtos que constantemente beneficiam a população fazem parte do processo do surgimento de novas tecnologias, que trazem mudanças profundas na sociedade.

A chegada dessas tecnologias produz um confronto entre a linguagem escrita e outras linguagens. Embora qualquer sistema utilizado como um meio de comunicação entre as pessoas possa ser considerado como uma linguagem, c cada uma difere em suas habilitações para expressar conceitos com precisão e com flexibilidade.

Jenkins (2009, p. 29) explica esse processo denominando-o de cultura de convergência, "onde as velhas e novas mídias colidem, onde mídia corporativa e mídia alternativa se cruzam, onde o produtor de mídia e o poder do consumidor interagem de maneiras imprevisíveis". São múltiplas plataformas de mídia gerando e divulgado conteúdos, cooperando entre si, incentivando o comportamento migratório do consumidor, que sempre está em busca de novas experiências de entretenimento.

Kanno (2013), é acrescentando informação visual e criando uma alternativa à narrativa convencional, em especial nas mídias impressas, que a infografia está avançando, colaborando para um jornalismo mais visual para atender aos consumidores de informação. Desde 1975 até os dias atuais, o computador vem abrindo novas fronteiras no jornalismo visual.

Assim, o infográfico tem extrapolado o seu uso inicial em jornais e revistas, passando a ser um recurso de comunicação empregado atualmente em diversas áreas, como educação, saúde, economia, marketing, entre outros. Pesquisas recentes mostram que a indissociabilidade entre e imagem e texto reforça quão benéfica para ambos é essa mistura na infografia em meio digital, valorizando a visualidade em articulação com as áreas do bilinguismo (educação, cultura e identidade surda) e da ergonomia (bem-estar dos usuários dos projetos). Pela combinação das linguagens verbal e não verbal, o infográfico constitui-se num sistema híbrido, multimodal. Também se verifica que, na América do Sul, países como a Argentina e o Brasil se destacam no cenário mundial da produção infográfica.

\section{Relação entre o verbal e o visual}

Para Pettersson (2012) o design da informação aborda esta relação entre o verbal e o visual na comunicação, com base na cooperação entre pessoas com competências e experiências prévias bem diferentes. Embora sua origem seja o design gráfico, a educação e o ensino, contempla também a apresentação clara e a interpretação fácil da informação.

Ainda de acordo com Pettersson (2012), as duas principais partes do design da informação e os dois principais componentes da mensagem são a infologia e a infografia, como se fossem duas faces de uma moeda. A infologia corresponde à parte teórica do design da informação e pode ser compreendida como a ciência da apresentação verbal, visual e a interpretação das mensagens. Já infografia está relacionada à prática do design da informação, com a execução de combinações estruturadas de palavras, imagens e design gráfico. "Um 
designer de mensagens precisa ter boas ferramentas compreensíveis por escrito, textos claros, tipografia consistente e layout que ajudará a captar atenção, percepção, interpretação, entendimento e aprendizado pelo receptor" (Pettersson, 2012, p. 38, tradução livre' ${ }^{1}$. Para Tufte (2005) -um dos precursores do conceito de visualização de dados-, o design de informações tem como tarefa principal enriquecer as exibições de informações e gráficos estatísticos, em geral realizadas em papel bidimensional e na tela do computador, com mapas de alta qualidade, detalhes diversos e abundantes, várias camadas de leitura combinadas com uma visão geral, e dados rigorosos de pesquisas de engenharia. Trata-se de "um progresso de métodos que melhora a densidade, a complexidade, dimensionalidade e, por vezes, a beleza" (Tufte, 2002, p. 33, tradução livre²).

$\mathrm{O}$ autor defende que o tratamento visual de dados influencia a maneira como as pessoas compreendem o mundo. Por isso as análises visuais devem sempre trazer comparações, tornando possível codificar a maior quantidade de dados possíveis usando a menor quantidade de recursos visuais e de espaço.

\section{Brasil e Argentina: o avanço do infográfico}

Uma vez que o infográfico contempla palavras e imagens que se complementam, um esquema bastante usual nas construções gráficas, o seu surgimento torna-se bastante impreciso (Moraes, 2013). No entanto, tratando-se do seu uso no jornalismo impresso, para tornar mais clara ao público uma informação, os anos 1980 são uma referência. Toda a produção anterior a esta época recebeu denominações diferentes, como mapa, gráfico de curva, gráfico de barra, perspectiva expandida.

Os infográficos se tornaram populares a partir da década de 80 do século XX, quando o USA Today apostou editorialmente no uso de textos curtos, formas inovadoras de cores, produção de mapas, gráficos, infográficos e outros recursos semelhantes. Os avanços tecnológicos também contribuíram para essas mudanças (Teixeira, 2010).

Nos jornais e revistas daquela época havia dois sistemas definidos: a linguagem verbal (os textos) e a não verbal (além do design, as fotografias e as ilustrações). Na interpretação de Moraes (2013), os infográficos apareceram exatamente neste contexto de mudanças: "Os infográficos representariam uma transição por se constituírem em sistemas híbridos, multimodais, que congregam ao mesmo tempo texto e imagem, linguagem verbal e não verbal numa relação em que se complementam mutuamente" (Moraes, 2013, p. 17).

A infografia deu origem a um novo tipo de discurso, que mescla texto e ilustração em uma unidade de espaço autossuficiente em sua capacidade de informar (Colle, 1998). Portanto, a informação contida de forma resumida num infográfico deve ser suficiente para que o leitor não recorra a um outro texto em busca de mais explicações. Há uma complementação entre as linguagens verbal e visual.

Os jornais espanhóis contribuíram para disseminar as reformas gráficas e editoriais -que contemplavam a infografia- na década de 1990. Moraes (2013) aponta que a Espanha trouxe novas referências e tendências, através dos trabalhos de Mario Tascón para o diário El Mundo e depois Jaime Serra, no jornal argentino Clarín. A diferença entre ambos é que 
Tascón baseava seus gráficos em desenhos vetoriais, enquanto Serra misturava desenhos vetoriais ou feitos à mão a produção fotográficas.

Os infográficos passaram então a ganhar versões digitais, não sem antes terem os infográficos impressos sido beneficiados por recursos mais sofisticados, como representação em três dimensões (3D) e a combinação com desenhos feitos à mão em um determinado número de páginas, numa única peça, os chamados megainfográficos.

Na década de 1980 as revistas passaram por profundas reformulações gráficas e editoriais, inclusive com consultorias de profissionais internacionais. A impressão passou a ser em cores, com os usos de infográficos e de novas tecnologias de editoração. "No que se refere à infografia, não se pode negar a importância da editora Abril no processo de implantação e desenvolvimento desse tipo de design no Brasil" (Moraes, 2013, p. 61).

Para enfrentar a influência da TV, os jornais que conseguiram permanecer no mercado também passaram por processos de reformulação, como a Folha de São Paulo (1984) que lançou o Projeto Folha, com profundas mudanças editoriais e gráficas.

Embora a editora Abril tenha recebido vários prêmios de infografia e design editorial com as reformulações implantadas, Moraes (2013) destaca que a grande contribuição da Abril foi a revista Superinteressante, que desde a sua criação, em 1987, privilegia os infográficos nas suas matérias, que passam por várias áreas do conhecimento.

As notícias mais “infografáveis” (Alonso, 1998, tradução livre³), preferidas pelos leitores, são as de interesse geral com abundância de dados, passíveis de serem transformadas em linguagem visual. Quando não há fotos suficientes, a infografia então ganha destaque.

Considerando a credibilidade uma das bases do jornalismo, os editores devem se basear em fatos corretos tanto para produzir os gráficos quanto textos e vídeos. Segundo Cairo e Giner (2011), na morte de Osama Bin Laden, algumas publicações mostraram como fatos o que era ficção, com muito sensacionalismo e poucos detalhes, como num show. Por isso, eles lançaram um manifesto, endossado até maio de 2011 por 58 profissionais de 22 países (Figura 1).

\section{O uso de infográficos}

A infografia tem ganhado cada vez mais espaço como ferramenta de comunicação e avançado para os formatos digitais. Podemos encontrar infográficos em áreas que jamais pensaríamos. Colle (2004) identifica que, além do jornalismo, outras áreas de aplicação do infográfico podem ser: manuais de instrução, que informam sobre procedimentos a serem realizados, partes de um produto e os cuidados na sua utilização; boletins de empresas, com informes anuais para diretores, sócios e acionistas; pedagógicos, que são parecidos com os manuais, mas cumprem melhor uma função educativa; e até publicitários, para divulgar empresas e seus produtos comercializáveis. 
6 REGRAS BÁSICASEÉTICAS

PARA A APRESENTAÇĀO DE INFOGRÁFICOS

\begin{tabular}{|c|}
\hline INFORMAÇŌES CONFIÁVEIS \\
\hline $\begin{array}{l}\text { Um infográficoé, por definição, uma apresentação } \\
\text { visual de fatos e dados. Por essa razão, nenhum } \\
\text { infográfico pode ser produzido na ausência de } \\
\text { informações confíiveis. }\end{array}$ \\
\hline $\begin{array}{l}\text { EVIDÊNCIAS DISPONIVEIS } \\
\text { Nenhum infográfico deve incluir elementos que } \\
\text { não sejam baseados em fatos conhecidos e } \\
\text { evidências disponiveis. }\end{array}$ \\
\hline $\begin{array}{l}\text { VERACIDADE } \\
\text { Nenhum infográfico deve ser apresentado como } \\
\text { sendo verdadeiro quanto é fictício ou baseado } \\
\text { em pressupostos não verificados. }\end{array}$ \\
\hline $\begin{array}{l}\text { CRÉDITO DA FONTE } \\
\text { Nenhum infográfico deve ser publicado sem o } \\
\text { crédito da sua fonte (s) de informação. }\end{array}$ \\
\hline $\begin{array}{l}\text { COERÊNCIA } \\
\text { Profissionais envolvidos na produção de } \\
\text { infográficos devem se recusar a fazer qualquer } \\
\text { apresentação visual que inclua componentes } \\
\text { fictícios destinados a tornar o infográfico mais } \\
\text { apelativo ou espetacular. Editores devem } \\
\text { abster-se da produção quando o pedido não se } \\
\text { atém às evidências disponiveis. }\end{array}$ \\
\hline $\begin{array}{l}\text { PADRŌES DO JORNALISMO } \\
\text { Infográficos não são ilustrações ou arte. } \\
\text { Infográficos são jornalismo visual e devem } \\
\text { se orientar pelos mesmos padrões éticos que } \\
\text { se aplicam a outras áreas de atividade. }\end{array}$ \\
\hline
\end{tabular}

Figura 1. Infográfico sobre o manifesto de Cairo e Giner sobre as regras básicas e éticas para a apresentação de infográficos. Fonte: Domiciano (2017, p. 87), baseado em Cairo;Ginner, 2011, tradução livre ${ }^{4}$.

\section{Ferramenta para traduzir a economia}

O Serviço de Proteção ao Crédito (SPC Brasil) lançou um portal para mostrar aos internautas, através de infográficos, a importância da educação financeira, com assuntos como o consumo consciente, o planejamento doméstico, o uso do crédito, as instruções aos filhos sobre finanças e uma relação saudável com o dinheiro. A economia é traduzida em informações visuais não somente para atrair o internauta, mas para que -através de uma nova linguagem- seja mais fácil para o consumidor entender a importância de cuidar bem do seu orçamento e também assimilar os princípios para uma administração eficiente. Quem compra um carro, por exemplo, deve estar atento a outras despesas (Figura 2). 


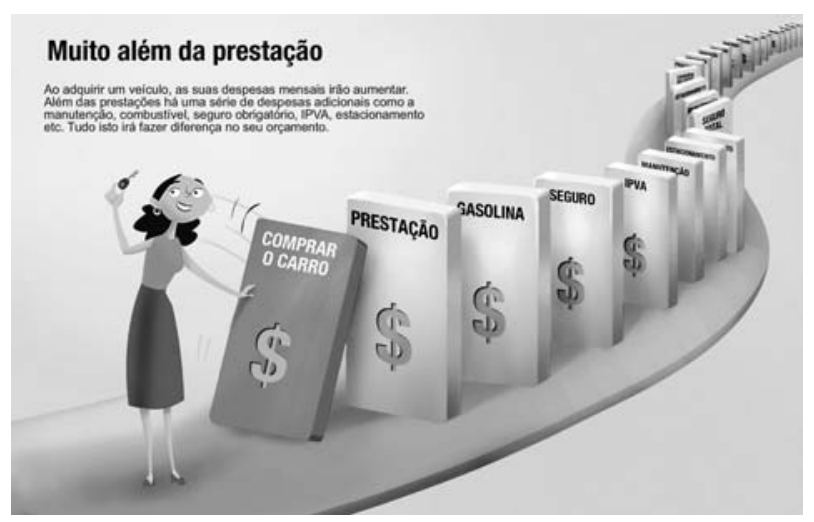

Figura 2. Infográfico sobre as despesas com carro divulgado no portal Meu Bolso feliz. O infográfico ganhou tal importância que pode ser facilmente encontrado em diferentes tipos de publicações, como nas divulgações de trabalhos artísticos ou de pesquisas científicas.

\section{Revista Zupi}

A revista Zupi ${ }^{5}$ (2013), por exemplo, lançou uma edição especial sobre infográficos com os materiais enviados por alguns dos seus mais de 200 colaboradores espalhados pelo mundo. A capa foi produzida pela empresa norte-americana Pop Chart Lab ${ }^{6}$, assim como um infográfico sobre os tipos de café expresso. Essa empresa inovou ao investir em gráficos visualmente atraentes, combinando conteúdo com design e combatendo o que seus fundadores, Patrick Mulligan e Ben Gibson, chamaram de "nítida falta de diversão" (Zupi, 2013, p. 27).

Entre outros trabalhos selecionados para a edição número 36, de 30 de agosto de 2013, estão o da brasileira Mayra Magalhães (https://pin.it/1Jy9hXi). Para ela, ao permitir a visualização de dados de maneira fácil e sistemática, o infográfico deixa de ser apenas uma tendência para se transformar numa necessidade, especialmente pela grande quantidade de informações consumidas. Sobre o futuro dos infográficos na mídia, Magalhães avalia que os infográficos "serão aplicados, também, em nosso cotidiano, com o advento e -possivelmente- popularização de tecnologias de realidade aumentada" (Zupi, 2013, p. 14).

\section{Uma agência de notícias infográficas}

Enquanto jornais de circulação nacional como Folha de São Paulo, O Estado de São Paulo, O Globo e outros importantes no cenário brasileiro investem de modo crescente na produção de infográficos, incentivando a criação de equipes multidisciplinares, a realidade em redações de jornais em cidade do interior do estado de São Paulo, por exemplo, é 
outra. Com estrutura e capacidade de investimento reduzidas, as principais publicações diárias recorrem a infográficos já prontos, que tratam de assuntos gerais e de interesse da maior parte dos consumidores.

A Graffo se apresenta como uma agência de notícias infográficas, que foge do sistema tradicional de distribuição de informações, com foco em assuntos brasileiros (http://www. forenseemercantil.com.br/2016/06/analise-informacoes_7.html). Além dos infográficos, também produz notícias em forma de caricaturas dos personagens do cenário nacional, matérias especiais sobre assuntos em evidência ou que tenham grande interesse do público, e reportagem digital, que é a versão para internet dos infográficos impressos, com recursos de animação e interatividade.

"Os infográficos são grande atrativo para a leitura das matérias. Facilitam a compreensão do texto e oferecem uma noção mais rápida e clara dos sujeitos, do tempo e do espaço da notícia" (Graffo, 2017). A empresa explica ainda os infográficos como quadros informativos com texto e ilustração que transmitem uma informação visualmente. Não só conta como a notícia, mas a mostra, trazendo detalhes mais relevantes e apelo visual.

No site da Graffo, o infográfico é apresentado como vedete nas principais editorias dos maiores periódicos do mundo, como The New York Times, The Times, El País, Clarín, Folha de São Paulo, Globo e Valor. Para os veículos que não têm uma editoria específica para a produção os infográficos, comprar as produções prontas -de acordo com a pauta oferecida diariamente- tornou-se uma opção viável. O pacote oferecido pela Graffo inclui de 10 a 15 infográficos diários, que são editáveis, e mais uma matéria especial mensal.

\section{Ferramenta de inclusão e saúde}

Como trabalho final da disciplina sobre sexualidade, 21 estudantes de medicina do Instituto Politécnico Nacional do México foram desafiados a produzir um infográfico sobre o aprendizado nas pesquisas com a comunidade LGBT, sigla para lésbicas, gays, bissexuais, travestis, transexuais ou transgêneros), conforme já publicado pelos autores em ... Os alunos usaram uma ferramenta online, o Picktochart, que traz modelos prontos e que podem ser editados pelo usuário.

O resultado final foi um infográfico que envolve as áreas de saúde e educação com o título "Processo de formação da identidade gay", que aborda o que é homossexualidade, as etapas desse processo (consciência de identidade, comparação, tolerância, aceitação, orgulho e, por fim, a incorporação de todos esses aspectos), dados sobre o tema no México e onde procurar apoio.

Quanto às ferramentas online para a produção de infográficos, existem outras além do Picktochart, como Cacoo, Canva, Createlly, Easelly, Infogram, Venngage e Visme, que se propõem a auxiliar o usuário na transmissão de uma mensagem visual que engloba textos e imagens. Elas apresentam variações sobre conteúdo textual, gráficos, mapas, ícones, fotos, vídeos, quantidade de modelos, design, facilidade de uso, gratuita e multimidialidade. Dentro de um projeto de prevenção à violência e acidentes de trânsito (Organização Mundial de Saúde [OMS], 2013) divulgou um relatório com dados daquele ano para incentivar medidas urgentes. São 6 infográficos contendo: estatísticas de acidentes em todo o mundo, 
as consequências de dirigir alcoolizado, velocidade, o uso de capacete pelo motociclista, cinto de segurança e proteção para as crianças.

De acordo com um dos infográficos produzido pela OMS sobre as consequências dos acidentes de trânsito (who.int/violence_injury_prevention/road_safety_status), morrem anualmente 1,24 milhões de pessoas no trânsito, principalmente na faixa etária entre 15 e 29 anos. No entanto, a probabilidade de falecer por acidente depende do local onde o condutor reside. As mortes a cada 100.000 habitantes correspondem a10,3\% na Europa, o menor índice, seguido das Américas, com 16,1\%. O índice mais alto está na África, 24,3\%. Quanto aos países que têm leis que estabelecem cadeiras de segurança para as crianças, cinto de segurança para os adultos e o limite de álcool igual ou menor que $0,05 \mathrm{~g} / \mathrm{dl}$ permitido no sangue do condutor (infográfico produzido pela OMS sobre a condução sob efeito do álcool: who.int/violence_injury_prevention/road_safety_status), praticamente toda a América do Sul está enquadrada nestes itens.

\section{Discussões}

O infográfico tem colaborado para a exploração de novas potencialidades no processo comunicativo, ultrapassando o formato editorial convencional. Ao combinar textos e imagens num processo de complementação, assume a propriedade de conduzir -no sentido de dar direção, transpor, comunicar-a informação até o público em geral.

A colaboração no processo comunicativo, no entanto, não se restringe à difusão de informações importantes, mas também ao processo de ensino e aprendizagem entre pessoas com deficiências diversas. Os idosos, por exemplo, podem ser orientados à prática de atividade físicas através de peças infográficas que os estimulem visualmente e contenham informações esportivas curtas e diretas. As crianças podem ser despertadas logo que entram na escola a entender as informações através de associações visuais, pelo uso de do uso de cores, imagens e textos. Inclusive, intervenções criativas quando direcionadas às minorias podem ajudar na inclusão social, facilitando a comunicação com e entre essas pessoas. Entre elas estão os surdos e mudos, que passam a ter a possibilidade de acesso ao mundo material ou virtual que os rodeia. Outro aspecto é na prevenção de doenças sexualmente transmissíveis, seja qual for a opção sexual do usuário de infográfico.

Nota-se ainda que o infográfico tem contribuído para a divulgação científica de uma forma efetiva, com sua utilização crescente em publicações, como na revista Pesquisa Fapesp, e impulsionando até a criação de agências, sejam elas de propaganda e marketing ou de notícias, que exploram os infográficos.

Outra tendência observada refere-se ao surgimento de várias ferramentas online para a elaboração de infográficos, como o Picktochart, que foi escolhido pelos estudantes de medicina no México para transmitir as informações sobre como se forma a identidade gay. Nessas ferramentas é possível utilizar modelos já prontos, a maioria disponibilizados por outros usuários, que permitem modificações. Embora, nesses casos, a originalidade se desvaneça, ganha-se em outros aspectos, como variedade de opções e agilidade. 


\section{Conclusões}

Fica evidente que o infográfico colabora para uma comunicação mais visual, sempre com a finalidade de informar e tornar mais claro o entendimento da realidade apresentada ao usuário. Ao permear áreas diversas do processo de comunicação, ultrapassando o jornalismo, torna-se, entre outras, uma versátil ferramenta educacional, em programas voltados para a área da saúde, no marketing, na inclusão das minorias, na divulgação esportiva, onde têm sido largamente aproveitado, como ocorreu nos Jogos Olímpicos do Rio de Janeiro, em 2016.

Além disso, o caminho dessa ferramenta tecnológica rumo à multimidialidade é irreversível, transpondo as peças estáticas para a exploração de vídeos, áudios, interatividade, hipertexto, realidade aumentada e a inserção de tecnologias já existentes e outras que ainda estão em processo de desenvolvimento.

É importante ressaltar, por fim, que após a troca de experiências entre profissionais brasileiros e expoentes da Espanha e dos Estados Unidos -através de cursos que foram oferecidos na década de 80 e anos seguintes-, a infografia brasileira passou a ganhar vários prêmios no Exterior e continua evoluindo.

Com esse crescimento do uso de infográficos tem mudado o perfil dos profissionais que atuam diretamente na sua produção, exigindo também que as universidades ofereçam disciplinas específicas dedicadas a esta área.

Portanto, o avanço tecnológico arrasta com ele mudanças profundas na forma do ser humano se comunicar e encaminha a infografia para um vasto horizonte a ser explorado.

\section{Notas}

1. Therefore a designer of messagens needs to have good skills in writing comprehensible, clear and consistente texts, in creating clear illustrations, and in creating a clear, transparente typography and layout that will aid attention, perception, interpretations, understanding and learning for the intended receiver (Pettersson, 2012, p. 38).

2. ...a progress of methods for enhancing density, complexity, dimensionality, and even sometimes beauty (Tufte, 2005, p. 33).

3. Infografiables (Alonso, 1998).

4. An infographic is, by definition, a visual display of facts and data. Therefore, no infographic can be produced in the absence of reliable information; 2. No infographic should include elements that are not based on known facts and available evidence; 3 . No infographic should be presented as being factual when it is fictional or based on unverified assumptions; 4. No infographic should be published without crediting its source(s) of information; 5. Information graphics professionals should refuse to produce any visual presentation that includes imaginary components designed to make it more "appealing" or "spectacular". Editors must refrain from asking for graphics that don't stick to available evidence; 6. Infographics are neither illustrations nor "art". Infographics are visual journalism and must be governed by the same ethical standards that apply to other areas 
of the profession" (Cairo).

5. A revista Zupi foi criada em 2001 para promover artistas do Brasil e do mundo, com curadoria de Allan Szacher. Começou na internet -www.zupi.com.br- e depois foi para o papel, em inglês e português, com distribuição em mais de 22 países. A partir da Zupi foram criados o Pixel Show (festival de criatividade), Zupi Academy (cursos e workshops para cerca de 8 mil alunos no Brasil) e o Zupi Awards (premiação internacional de arte e criatividade) (Fonte: http://www.zupi.com.br/revista-de-arte-e-criatividade-zupi/).

6. Fundada em 2010 por Patrick Mulligan, diretor editorial, e Ben Gibson, diretor de criação, a Pop Chart Lab comercializa infográficos com uma linguagem própria, transformando-os em pôsteres e camisetas. A sede da empresa fica no Brooklyn, em Nova York (ZUPI, 2013, p. 25).

\section{Bibliografia}

Alonso, J. Grafía. (1998). "El trabajo en una agencia de prensa especializada en infográficos" em Revista Latina de Comunicación Social, número 8. Disponível em http://www.ull.es/ publicaciones/latina/a/49inf6.htm. Acesso em 10/07/2016.

Cairo, A. \& Giner, J. A. (2011) "Editors, artists chafe at the errors and hype in bin Laden death story graphics", em Nieman Watchdog. Disponível em http://www.niemanwatch dog.org/index.cfm?fuseaction=showcase.view\&showcaseid=152. Acesso em 18/02/2019.

Colle, R. (1998). “Estilos o tipos de infografos”, em Revista Latina de Comunicación Social, número 12. Disponível em http://www.revistalatinacs.org/a/02mcolle/colle.htm. Acesso em 18/02/2019.

Colle, R. (2004). “Infografia: tipologias”, em Revista Latina de Comunicación Social, número 58. Disponível em http://www.ull.es/publicaciones/latina/latina_art660.pdf. Acesso em 20/11/2016.

Domiciano, M.A.L. (2017). A condução da informação da linguagem cientifica ao infográfico. 221f. Dissertação (Mestrado Profissional em Mídia e Tecnologia) - Universidade Estadual Paulista Júlio de Mesquita Filho (Unesp), Bauru.

Domiciano, M. A. L.; Valente, V. C. N. P.; Domiciano, C. L. C. (2018). “Tecnologia assistiva e infográfico: contribuição para a comunicação em educação e saúde”, em Medola, F. O.; Paschoarelli, L. C. Tecnologia Assistiva: Estudos Teóricos. Bauru: Canal 6 editora, $1^{\text {a }}$ ed., 2018, p. 379-389.

Graffo. (2017) O que é infográfico. Disponível em http://graffo.inf.br/infografico/. Acesso em 18/02/2019.

Jenkins, H. (2009) Cultura da convergência (2a ed.) São Paulo: Aleph.

Kanno, M. (2013). Infografe: como e porque usar infográficos para criar visualizações e comunicar de forma imediata e eficiente. São Paulo: Infolide.com

Moraes, A. (2013) Infografia: história e projeto. São Paulo: Blucher.

OMS. (2013). Prevención de la violencia y los traumatismos. Disponível em https://www.who. int/violence_injury_prevention/road_safety_status/2013/facts/es/.Acesso em 18/02/2019. 
Pettersson, R. (2012). It depends: principles and guidelines. IIID Public Library, Tullinge. Disponível em http://www.iiid.net/PublicLibrary/Pettersson-Rune-ID-It-Depends.pdf. Acesso em: 18/02/2019.

Teixeira, T. (2010). Jornalismo e infografia. Salvador: Edufba.

Tufte, E. W. (2005). Envisioning information. Cheshire, Connecticut: Graphic Press.

Zupi: revista bimestral de arte e criatividade. (2013). Special edition infographics. São Paulo: editora Zupi, n. 36, 99p.

Resumen: El texto examina cómo el avance tecnológico beneficia a las infografías en el proceso de comunicación e inclusión de las minorías. El objetivo es analizar algunas piezas infográficas producidas en Brasil, Argentina y México para detectar sus funcionalidades como herramienta tecnológica que se apoya en la complementariedad entre verbal y visual para transmitir informaciones. La evolución de los infográficos en Brasil ha colocado al país en la vanguardia de la producción en América Latina, extrapolando el uso inicial en periódicos y revistas para abarcar economía, marketing, deportes, salud, enseñanza, aprendizaje e incentivar las relaciones personales. Se discuten las reglas éticas para presentación de infografías y de qué manera las herramientas en línea han colaborado para que los laicos en el asunto puedan involucrarse en la producción. Al incorporar videos, audios, interactividad, hipertextos, realidad aumentada y otras tecnologías, la infografía asume su multimedialidad y abre el camino para posibles nuevos cambios en el proceso de comunicación.

Palabras clave: infografía - inclusión - herramienta de comunicación.

Abstract: The text examines how from technological advances benefit the infographics in the process of communication and inclusion of minorities. The objective is to analyze some infographic pieces produced in Brazil, Argentina and Mexico to detect their functionalities as a technological tool that relies on the complementarity between verbal and visual to transmit information. The evolution of infographics in Brazil has put the country at the forefront of production in Latin America, extrapolating the initial use in newspapers and magazines to encompass economy, marketing, sports, health, teaching, learning and encourage personal relationships. It discusses the ethical rules for presentation of infographics and how the online tools have collaborated so that lay people in the subject can get involved in the production. By incorporating videos, audios, interactivity, hypertexts, augmented reality and other technologies, the infographic takes on its multimedia nature and opens the way to possible new changes in the communication process.

Keywords: infographic - inclusion - communication tool.

[Las traducciones de los abstracts fueron supervisadas por el autor de cada artículo] 